\title{
Blue Sky Fabrication in China: Science-Policy Integration in Air Pollution Regulation Campaigns for Mega-Events* $\square$
}

How does the Chinese government, on occasion, manage to spirit away China's immense air pollution problem? In order to ensure that blue skies will greet participants in international mega-events in China, such as the 2008 summer Olympic Games, the 2014 APEC summit, and the G20 summit in 2016, host cities and surrounding regional governments have often implemented stunningly comprehensive plans for controlling air pollution which have usually included the halting of industrial production, the restriction of traffic, the suspension of construction work, and the relocation of residents. These plans are formulated and implemented for a defined period of time only, and they seem to represent an ad hoc topdown campaign-style of governance, rather typical of Chinese politics. In contrast to traditional political campaigns in China, however, governance campaigns nowadays involve a much more significant level of scientific knowledge and steering. For the current "blue sky" campaigns, for instance, environmental engineers are invited to design and oversee measures for smog and air quality control in close collaboration with local authorities, while political scientists are consulted to mitigate the potential risk of any public backlash against the harsh regime of pollution control. We argue that the integration of policy and science that occurs for the purpose of alleviating air pollution during these events deserves specific attention with regard to what can be learned about the incorporation of scientific knowledge into policy making in China and its tangible effects. Based on a study of the G20 summit that was held in Hangzhou in September 2016, this article explores how, under this special form of pollution control enforcement, the government regionally mobilized public (and especially scientific) resources to fabricate blue skies. Some of the sustainable effects of science-policy integration for implementing impromptu air pollution control are also examined.

keywords: China, science-policy integration, air pollution control, policy implementation, campaign-style governance, G20 Blue 


\section{Introduction}

Air pollution is one of the most serious environmental concerns that China is facing. Smog, or, more precisely, particulate matter pollution clogs China's cities and towns. In 2014, the Chinese Prime Minister, Li Keqiang, announced that the Chinese government was declaring "war against environmental pollution", and while studies show that the tremendous efforts undertaken during the initial years of China's Action Plan for the Regulation and Control of Air Pollution (also in 2014) have already yielded some positive effects, air quality is still poor and haze is omnipresent; in fact, skies over China are grey on most days of the year (Ahlers \& Hansen, 2017; Aunan, Hansen \& Wang 2017).

Occasionally, however, the heavens seem to relent and the haze disappears, allowing a bright sun to shine in a blue sky - surprisingly enough, this always seems to occur at exactly the same time as a high-profile political summit, important national celebrations and international events. It was long suspected that this apparently coincidental, almost mystical clearing of the skies was in fact politically-fabricated, but only since the 2008 Olympics in Beijing has this fact been openly admitted by the government authorities (Hsu, 2014). The occasion of the 2008 Olympics was also the first time that related regulatory measures, such as the halting of industrial production in a particular vicinity, the restriction of traffic and the suspension of construction work, were openly undertaken to such an unprecedented degree. Since that time, the government's plans for clearing the skies, as well as (most of) the related necessary measures undertaken to achieve this, have been publicly announced, for instance, for the 2010 World Exposition (Expo) in Shanghai, the 2014 APEC meeting, the 2015 Victory Day military parade in Beijing, and the G20 summit in Hangzhou in 2016.

Ad hoc planning for smog clearance and air quality improvement represents a tremendous challenge. Not only do local authorities need precise knowledge about the main pollution sources and the necessary measures required to regulate or even eradicate the polution, but also do the preparations for the previously-mentioned mega-events often interfere with critical activities in the economic sector and with city residents' lives and daily routines. At the very least, this means that "blue sky" measures need public compliance, be this voluntary or coerced. Hence, in recent years, the governments involved have officially called for the public to contribute towards clearing up the skies on the occasion of high profile events in recent years, for example, by externally contracted scientific experts or the general population. These actions have usually been successful, to some extent, so that host cities have been able to present themselves under relatively clear blue skies in time for the events, and these 
achievements have often gained recognition, retrospectively, in the form of descriptions such as "APEC Blue" which refers to the clear skies over Beijing during the APEC summit in 2014. But just how is this ad hoc planning for smog regulation and air quality control for megaevents actually put into practice?

In this article, we look at "blue sky" fabrication less as a type of technical geo-engineering 1 than as an administrative endeavor and a governance problem. We find that the way these blue sky controls evolve and are put into action is reminiscent of a political campaign, or, more precisely, of what observers of contemporary Chinese politics call campaign-style policy making or campaign-style governance. We are particularly interested in the policy tools that are employed and the ways in which science and technology are adopted in the overall formulation of action plans and operational processes when a government is tasked with rapidly creating temporarily smog-free venues. What is the status and the role of the externally-contracted scientists and experts who participate in these ad hoc campaigns? How is scientific expertise used for the legitimation of harsh measures vis-à-vis the broader population? And are there any sustainable effects stemming from scientific influence on this form of campaign-style top-down policy making in China?

This article builds on the research that we conducted in Hangzhou, Zhejiang Province, on the particular case of the “G20 [summit] Blue” (“G20 蓝”) in September 2016. ${ }^{2}$ We combine three main types of data: the analysis of policies and plans for air quality control during the summit, semi-structured in-depth interviews with scientists and policymakers, and real-time air quality data for the region and period under review. In particular, we have studied the policy preparations that were implemented in 2015 and 2016 before the summit, and we have carried out a retrospective analysis of the outcome in $2017 .{ }^{3}$ We conducted interviews with eight officials from Hangzhou City's Environmental Protection Bureau, Hangzhou City’s

\footnotetext{
${ }^{1}$ Science-policy integration is not a new challenge in environmental engineering and governance, see, e.g. Farish, 2013. Recently, geo-engineering has increasingly been employed in the field of climate protection governance; see, e.g., Schubert, 2018.

${ }^{2}$ As a result of our contacts with a group of experts and scholars who are involved in scientific consultancy for impromptu measures to tackle air pollution, we were able to ask them to share their experiences with us and, by this means, obtained some insights into different cases of blue sky fabrication in China, especially those that were previously staged in Beijing (APEC, military parade). On this basis, in the long-term, we aim to produce further, more comprehensive comparative research on this topic.

${ }^{3}$ During our fieldwork in the run-up to the G20, in late spring 2016, we experienced the heightened security measures first-hand and had to scale down our research ambitions. This meant that we were not able to be on site during the G20 week, because Hangzhou introduced travel restrictions for foreigners and the city basically turned into a kind of open-air museum where very few residents were allowed to move around freely, as has been widely reported in the international media. See, e.g., Campbell, J. (2016), China's Hangzhou turns ghost town as G20 leaders arrive, Reuters, 3 September; available at: http://www.reuters.com/article/us-g20-chinahangzhou-idUSKCN11906S (accessed 15 Juni 2017). In general, all the measures related to the summit were treated as highly confidential and sensitive, including all the aspects related to environmental pollution control.
} 
Transportation Bureau, the Zhejiang Provincial Environmental Protection Bureau, and with six scientists, two of whom work at Tsinghua University, two at Zhejiang University, one at the Zhejiang Research Academy of Environmental Science, and one at the Chinese Research Academy of Environmental Science. These scientists were either directly involved in the "blue sky task forces" or observed the events as scholars of governance or environmental engineering. Two leaders of environmental NGOs, Greenpeace and Green Zhejiang, and a dozen Hangzhou City residents were also interviewed. In addition, we collected the available real-time data on PM2.5, $\mathrm{SO}_{2}$ and $\mathrm{NO}_{2}$ from official websites both before and after the G20 summit in Hangzhouas as well as on the tangible effects of the ad hoc methods employed to control these measures locally.

The remainder of the paper is organized as follows: we begin with a brief review of the existing literature on contemporary policy campaigns and campaign-style governance in the People's Republic of China. On the basis of this information, we present an analysis of the local government's adoption of science and public mobilization for the smog clearance and pollution control policy related to the 2016 G20 summit in Hangzhou. We conclude the article with a short analysis of the potentially sustainable outcomes of campaign-style environmental governance that we encountered and a brief examination of its apparent legitimacy in China.

\section{Campaign-Style Governance of Air Pollution Control During Mega-Events in China}

Conceptually, we treat event-related "blue sky" fabrication as a type of campaign-style governance, i.e. highly centralized (administrative) resource mobilization under political sponsorship for the purpose of achieving specific policy goals within and for a defined period of time (Liu, et.al, 2015). Campaigns have a long history in the People's Republic of China, but their form as well as mode of application has changed considerably over time. During the Mao era, they aimed at nothing less than mobilizing society as a whole, while when they occur today, political campaigns are usually formostly addressed at the state apparatus, i.e. especially Party and government organizations at all levels of the political hierarchy and ultimately at cadres - in other words: the implementors of the policy goals at stake. Accordingly, Elizabeth Perry (2011) has called this transformation "from mass campaigns to managed campaigns". Moreover, contemporary campaigns, or better: campaign-style politics, mainly take the form of (a) disciplinary, supervisory and sanctioning campaigns, such as anticrime campaigns (Tanner, 1999, 2005), or the recently reinforced anti-corruption campaign (Wedeman, 2005; Zhu \& Zhang, 2017), or (b) regulatory enforcement or policy/goalattainment acceleration campaigns (Guo \& Foster, 2008). While the first type of campaign 
shows variation on a spectrum between a loose initiative model and a pervasive "strike hard" approach - often with a moralistic undertone - that can linger on for a relatively long period, the latter tends to be more ad hoc and temporary in nature and often concerns more matter-offact policy fields, such as economic and environmental regulation and their coordination and ultimate implementation (Rooij, 2006; Biddulph, Cooney \& Zhu, 2012). Taken together, some common characteristics of the policy enforcement types of campaign as identified in the existing literature are:

- a clearly defined goal,

- political sponsorship,

- a high degree of urgency,

- a defined period of time,

- a tightly coordinated operation,

- pooling of (extraordinary) resources,

- and public involvement.

Although campaign-style governance is a topic of interest in research literature, current research has not yet provided sufficient insights into the actual mechanisms of the campaignstyle enforcement of environmental governance during mega-events. The ways in which environmental concerns are usually addressed and dealt with in the event planning and management cycle have been well-documented (Caratti \& Ferraguto, 2012), but the ways in which administrative power is distributed and resources are mobilized for the specific goal of impromptu smog clearance and air pollution control, which has recently become a top priority for mega-event planning in China, require further examination. In particular, multi-actor interfaces, such as (in our case), the interaction between political authorities and science/scientists, as well as the possible effects of these campaigns beyond the events themselves, warrant more research.

So far, we would claim that the above-mentioned general characteristics and elements apply to the specific type of campaign-style enforcement that we have observed in mega-event related air pollution control in China. However, we state that, for this variant, the temporal aspect (i.e. a specific event and a clearly defined period of operation) is even more central, and (externally contracted) scientific expertise becomes particularly crucial. General public involvement, at the same time, is largely absent, or only appears in the form of addressing the public with negative restrictions, or in enlisting some members of the public to support action. This again bespeaks what is probably the clearest difference to traditional, Mao era political 
campaigns: contemporary campaign-style governance usually does not aim at mobilizing the overall (lay) public, or the mass of the general population, as such, but addresses professional implementors or selected target groups which are perceived as being necessary for a specific purpose.

Other, more specific observations during "blue sky fabrication" that mirror the characterics of campaign-style governance identified above can be summarized as follows: International political summits and competitions are always considered mega-events for China and since the 2008 Olympic Games, at least, there has been central political sponsorship for the goal of smog and air pollution control during these events for the purpose of international reputation and image-building. Mega-event related air pollution control definitively involves urgency, not only because this is a by-product of the sheer ambition to create blue skies where typically there are none, but also because the control is supposed to take effect for a specifically defined period, and sometimes even on one specific occasion.

Mega-event "blue sky" action planning builds on resource pooling of many sorts. Most of the mechanisms involved in campaign-style governance are observable in the lower echelons of the political structure which are tasked with the immediate implementation of related measures. As a matter of fact, ambient air pollution's relative "measurability" may assist an indicator-based assessment of campaign-style regulation enforcement on the occasion of mega-events (Ahlers \& Hansen, 2017). There is, in particular, a considerable degree of 'scientific' expertise, which is mobilized at multiple levels and is supposed to assist the government in detecting pollution sources, designing models for temporary air quality regulation, monitoring the effectiveness of measures during the event and reacting in times of crisis.

Moreover, knowledge of social sciences, in particular, public administration studies, is sought to promote the adequacy and legitimacy of extraordinary measures during the mega-events. The central premise of campaign-style enforcement is that power adequacy can be temporarily created by the extraordinary employment of regulatory orders for other societal stakeholders. This also entails that ad hoc smog clearance does not provide for (or better, must avoid) any participatory mechanism that is intended to include stakeholders, i.e. no public deliberation of measures, and no bargaining with factory owners. The government, through enforced scientific propaganda and education efforts, simultaneously lobbies for the legitimacy of these extraordinary measures by attempting to convince affected residents that they should feel honored to sacrifice some individual freedoms in order to support the 
successful collective staging of high profile international events. "A good host, a better G20" (做好东道主, 办好 G20), was the slogan chosen for Hangzhou city, for instance. The bottom line is that, in order to fabricate blue skies for a specific event, only concerted and pointed compliance counts; any distraction or disturbance, nowadays usually tolerated in the Chinese policy process, is unacceptable (Gilley, 2012).

We will now delve deeper into our analysis of the "blue sky fabrication" measures and mechanisms that accompanied the 2016 G20 Hangzhou summit, and explain, in particular, how science and scientists are incorporated into the process.

\section{A Case Study: Smog and Air Quality Control During the 2016 G20 Hangzhou}

\section{Summit}

Less than $1 \%$ of China's 500 cities have attained the air quality standard recommended by the World Health Organization (WHO). The WHO primarily measures air quality by the amount of small particles present, known as PM2.5, that can enter the lungs and blood vessels and can potentially lead to long-term health damage. But PM2.5 - together with a complex mix of other chemical as well as meteorological factors ${ }^{4}$ - also creates visible pollution, referred to a smog: the lower the concentration of PM2.5 in the air the bluer the sky appears.

The host city of the 2016 G20 summit in China, in Hangzhou, is recognized as one of China's most attractive destinations, but like many others, it struggles with intense air pollution, ranking only 43rd out of 74 cities in a 2014 study of air quality measurements compiled by Greenpeace. . Hangzhou had 115 "bad air quality days" in 2016, and a daily average concentration of PM2.5 of $60 \mu \mathrm{g} / \mathrm{m}^{3}$ on an annual basis in $2016 .{ }^{6}$ For the G20 summit, the upper limit of PM2.5 was set at $35 \mu \mathrm{g} / \mathrm{m}^{3}$ to ensure blue skies over Hangzhou, in line with the indicators used in the 2012 Chinese National Ambient Air Quality Standards (NAAQS, Class II). ${ }^{7}$ Clearly, the parties involved had to tackle the huge gap between these two measurements in order to fulfil the goal of temporary pollution regulation set for the summit (Table 1).

\footnotetext{
${ }^{4}$ For a good description of the complexity of the smog problem and what this means in terms of positing natural phenomena against policy intervention see e.g. Gao et al., 2017; Liu et al., 2017.

${ }^{5}$ Greenpeace (2014), Ranking 74 Chinese cities by air pollution, available online:

http://www.greenpeace.org/china/zh/news/releases/climate-energy/2014/01/PM25-ranking/ (accessed 16 June 2017).

${ }^{6}$ Data obtained from Hangzhou City's Environmental Protection Bureau's reports, available at: http://www.hzepb.gov.cn/zwxx/gkml/14/1402/201706/t20170616_57486.htm (accessed 16 June 2017).

7 The Chinese Ministry of Environmental Protection issued the new National Ambient Air Quality Standard (2012 NAAQS) on 29 February 2012. The 2012 NAAQS sets PM2.5 concentration limits for both the 24-hour average and the annual mean value. The 24-hour average concentration limited value is $35 \mu \mathrm{g} / \mathrm{m}^{3}$ for Class I locations, including natural protection zones, scenic resorts, and other areas needing special protection, and
} 
Table 1: Daily average concentration of PM2.5 year on year from 2013 to 2016

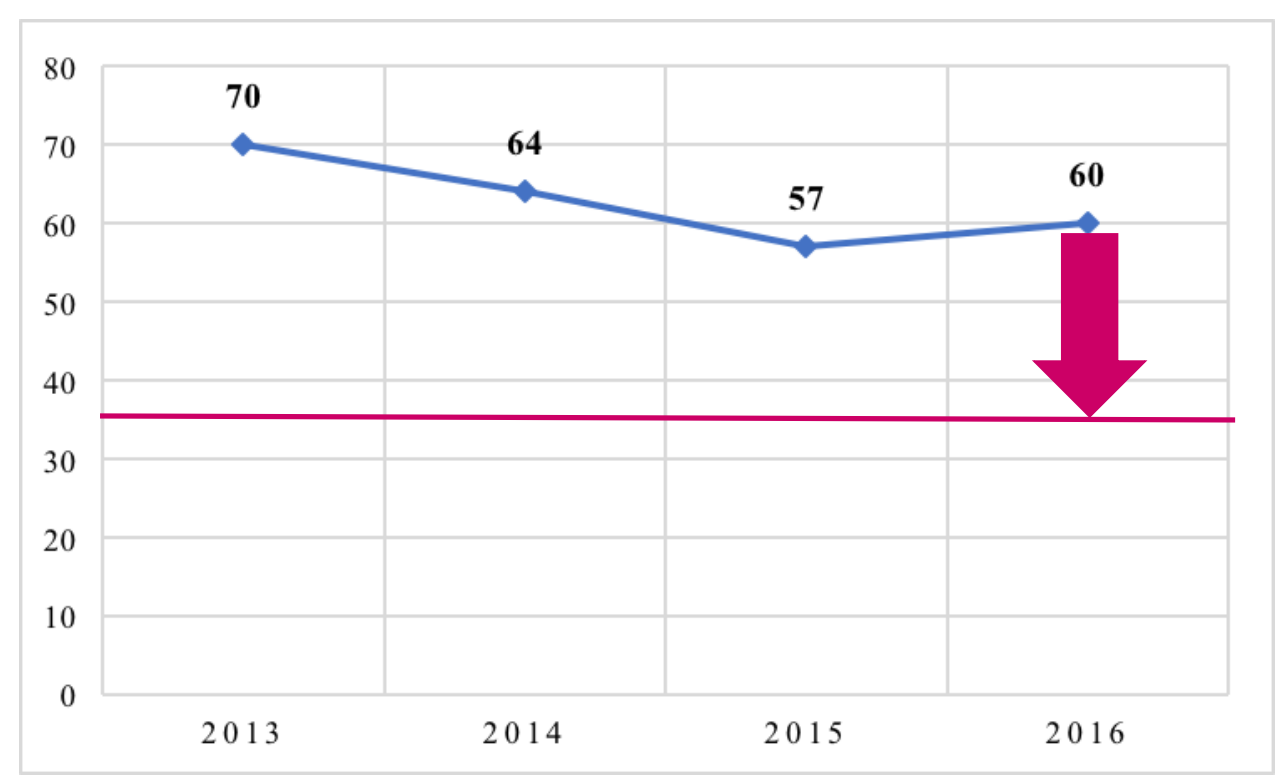

Source: Annual bulletins of the status of the environment in Hangzhou city from 2013 to 2016; see, for example, the bulletin for 2015, available at: http://www.hangzhou.gov.cn/art/2016/7/5/art_1209291_3816.html (accessed 17 June 2017). The red line indicates the Class II standard under NAAQS.

\subsection{Setting Specific “Blue Sky” Campaign Goals}

First and foremost, for the campaign-style governance of air quality control during the G20 summit (hereafter called "G20 Blue"), an overall target in terms of achieving NAAQS Class II for the duration of the G20 summit was set, which meant a PM2.5 concentration of less than $35 \mu \mathrm{g} / \mathrm{m}^{3}$ on an annual average and less than $75 \mu \mathrm{g} / \mathrm{m}^{3}$ per day, in addition to other indicators, such as an $\mathrm{O}_{3}$ concentration of less than $200 \mu \mathrm{g} / \mathrm{m}^{3}$ per hour, and of $\mathrm{NO}_{2}$ under 40 $\mu \mathrm{g} / \mathrm{m}^{3}$ on an annual basis. The Ministry of Environmental Protection (MEP) announced that during the G20 summit, the host city, Hangzhou, would be "the centre of China" and that all the jurisdictions around Hangzhou City should spare no effort to comply with the G20 Blue related tasks. In other words, Hangzhou's city government and the relevant organs of Zhejiang's provincial government were handed full responsibility for achieving these specific air pollution regulation goals.

The particular period of air quality control action was set as from 24 August 2016 to 6 September 2016, although much preparation was carried out before the start of this period (Fig. 1). Three different "control zones" were identified around the G20 conference site: the

$75 \mu \mathrm{g} / \mathrm{m}^{3}$ for all other locations (Class II locations). The annual mean value of $15 \mu \mathrm{g} / \mathrm{m}^{3}$ is for Class I locations and the value of $35 \mu \mathrm{g} / \mathrm{m}^{3}$ is for Class II locations. 
core area (核心区), with a $50 \mathrm{~km}$ radius around the conference site, a so-called restricted area (严控区), with a radius of $100 \mathrm{~km}$, and the control area (管控区), with a radius of $300 \mathrm{~km}$; all the zones beyond the core area were also designated a cooperation area (协作区) (Fig. 2). Some general guidelines were established for special application in the core area and the restricted area during the target period. These measures included the closure of power plants and polluting factories, the restriction of car and bus traffic on the roads, and the halting of construction projects.

Figure 1: Official milestones during the process of air quality control during the 2016 G20 Summit
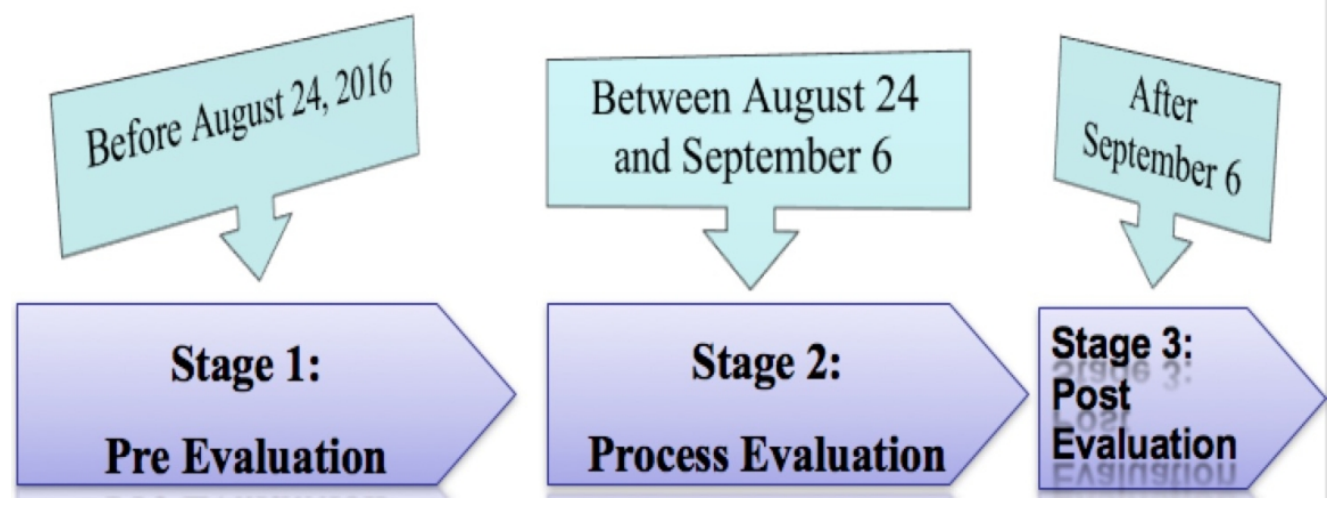

Figure 2: The four control areas for air quality regulation during the 2016 G20 Summit

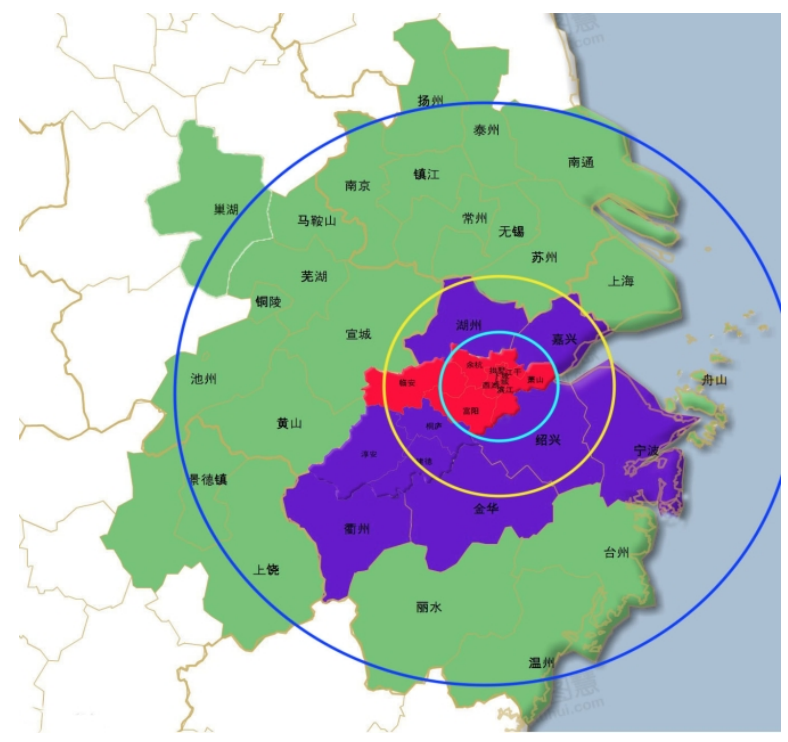

Source: Authors' own illustration. 


\section{Zhejiang Province}

Zhejiang's provincial government became the operational center of major support actions for G20 Blue and coordinated measures between different cities in the province. This also included obtaining and organizing relevant scientific expertise. The primary necessity was to locate the main air pollution sources affecting Hangzhou's air quality and haze development. The provincial level EPB contracted out projects to investigate polluting sites and produce pollution source lists that served as the basis for any pollution control action taken during the campaign period. Scientists from Zhejiang University, Tsinghua University, Nanjing University, the Chinese Academy of Sciences Shanghai Branch, the Chinese Research Academy of Environmental Sciences, and the Zhejiang Research Academy of Environmental Sciences were invited to contribute to the overall data pool by locating and collecting samples from pollution sources within Zhejiang Province, while other colleagues assisted with source apportionment. After receiving the map of pollution sources, the provincial government asked local governments to work towards temporarily stopping all key polluting industries in the core control area and to reduce emissions from other industries in the core control area and the restricted area by $50 \%$. Consequently, all construction work was suspended in the core control area and restricted area.

Within Hangzhou City, according to the initial pollution source detection work undertaken by scientists, $28 \%$ of general air pollution was due to transportation activity, $23 \%$ stemmed from industry, 20\% was dust, 19\% was reportedly due to coal burning, while other small-scale activities such as cooking supposedly accounted for $10 \% .{ }^{8}$ It was therefore decided that vehicle exhaust emissions, industrial emissions, dust production and certain household activities were the main pollution sources that Hangzhou city government would have to tackle, and the following enforcement measures were implemented between 26 August and 6 September 2016:

(1) Hangzhou city government temporarily shut down industries which were associated with the above-mentioned high pollution risks. More than 200 steel mills in surrounding districts were shut down as part of the bid to limit pollution during the summit. One state-owned company, called Hangzhou Iron \& Steel Group, which had previously produced emissions containing around 7,000 tons of sulphides, 3,400 tons of oxynitrides and 3,000 tons of dust

\footnotetext{
${ }^{8}$ Data obtained from Hangzhou City's Environmental Protection Bureau's reports, available at: http://www.hzepb.gov.cn/zwxx/gkml/14/1402/201706/t20170616_57486.htm (accessed: 16 June 2017).
} 
every year, even closed down its base in Hangzhou permanently under the pressure of the G20 Blue plan. ${ }^{9}$

(2) An odd-even license plate driving restriction policy was implemented to reduce the number of cars on the roads for the duration of the G20 summit. Private motor vehicles with Hangzhou local license-plates (浙 A) entering Hangzhou city were required to obtain temporary permits or passes, while vehicles with non-Hangzhou license plates were banned in the city area. In addition, the use of all "yellow label cars" (黄标车) on the streets that failed to meet the National Emissions Standard was forbidden. For example, buses using diesel fuel, whose exhaust emissions failed to meet the latest national standards, were simply taken off the roads. More than 2000 e-buses were put into service to replace petrol-driven buses. ${ }^{10}$

(3) All construction activity in Hangzhou was held since it would disperse sand and other dust-like particles, and seriously reduce air clarity. Main roads and streets were sprayed with water frequently in order to prevent dust dispersion.

(4) With regard to human activity and its impact on air quality, two million out of a total of nine million local residents were encouraged to leave Hangzhou city for a special vacation (see also below). Restaurants in Hangzhou which did not use filters to mitigate kitchen emissions were ordered to close.

Other cities in Zhejiang Province also enforced a campaign-style action plan to help reduce overall air pollution and safeguard the G20 Blue, for example, Shaoxing city, located at a distance of 63 kilometers from Hangzhou, and home to numerous extensive industrial facilities in fields such as chemistry, printing, dyeing and powder coating as well as thermal power plants. It was estimated that the air pollution produced by facilities in Shaoxing City would endanger the G20 Blue, since the pollutants would travel from Shaoxing to Hangzhou. In order to avoid this, the Shaoxing municipal government was asked to make all efforts to reduce air pollution during the G20 Blue action period: Firstly, already before June 2016, the Shaoxing EPB itself investigated air pollution sources by checking up on the pollution control means of more than 3,000 factories in its jurisdiction. Secondly, the Shaoxing municipal government established 49 additional monitoring stations for PM2.5 around its industrial and most pollution-heavy areas. A further 8 stations for full AQI (Air Quality Index)

\footnotetext{
${ }^{9}$ Sohu News (n.a.) (2015), Hangban factory in Banshan shutting down completely 59 years after it was built (建 厂59年“杭钢”半山基地全线关停), 23 December, available at http://news.sohu.com/20151223/n432377278.shtml (accessed 18 June 2017).

${ }^{10}$ Interview with an official from Hangzhou City's transportation department in February 2017; China Jiangsu Web (n.a.) (2016), Green G20: Coordination in the Yangtze Delta Area to Ensure 'G20 Blue' (绿色 G20, 长三 角协作防治确保“G20 蓝”), Jiaohuidian (交汇点), 25 May, available at http://js.xhby.net/system/2016/05/25/028782270.shtml (accessed 18 June 2017).
} 
measurements were built in key industrial parks to allow for real-time air quality monitoring in early July 2016. Finally, by adhering to these air quality controls on the basis of the new network of measuring stations, Shaoxing, by June 2016, had managed to reduce air pollution stemming from more than 525 coal-fired boilers, and more than 100 industrial factories were required to continually reduce their VOC emissions, even after the end of the G20 Blue campaign period. ${ }^{11}$

\subsection{Data-based Regional Coordination in the Wider Yangtze Delta Area}

In the run-up to the G20 summit, scientific models were produced which located the major pollution sources that impacted air quality and smog concentration in Hangzhou. According to these calculations, contribution to PM2.5 output from within the city area stood at $72 \%$, while the regional transport of particles accounted for the remaining $28 \%$. These were mainly said to come from Jiangsu province (51\%) in the northern wind direction, Shanghai City (15.78\%) and Jiangsu Province (12.56\%) in the northeastern direction, Anhui province (20.46\%) in the northwestern direction and other cities of Zhejiang province $(34.08 \%)$ in the southern wind direction. In fact, the Yangtze River Delta Area Cooperation Group for Air Pollution Protection, consisting of leaders from Shanghai city, Zhejiang, Jiangsu and Anhui provinces, played an important role in coordinating air pollution regulation enforcement work. They oversaw the first coordinating conferences and produced collaboration plans for the entire Yangtze River Delta area on which intergovernmental cooperation was based. On this basis, Jiangsu and Anhui provinces and Shanghai city carried out their air pollution control measures separately. All these governments came up with their own "G20 summit environmental air quality guarantee” (G20 峰会环境空气质量保障方案). Shanghai’s scheme, for instance, required that, between 24 August and 9 September 2016, coal power plants in the city be strictly controlled and required to reduce their production levels by $30 \%$. Other key polluting industries that were included on a name list of 255 companies which discharged $80 \%$ of the measurable air pollution in Shanghai, were closed or had to reduce production, among them, for example, Sinopec Shanghai Petrochemical Company Ltd., which was asked to reduce its production by $50 \%$. In addition, the city had to follow the other control measures laid out in the MEP's general guidelines, such as restricting heavily-polluting vehicle traffic and increasing the frequency of road cleaning and sprinkling, as well as controlling dust dispersion at construction sites.

\footnotetext{
${ }^{11}$ Special Issues for Hangzhou G20 Summit Environmental Quality Improvement, Zhejiang Provincial Government, Doc. no. 4, 25 July 2016, available at http://www.zjepb.gov.cn/hbtmhwz/sylm/zxdt/201607/t20160725 424552.htm (accessed 19 June 2017).
} 
Altogether, however, the coordination of control measures in the Yangtze Delta Area did not have a particularly fixed or static structure but, instead, followed a flexible process, as was pointed out to us on several occasions. For example, a professor of environmental engineering at Tsinghua University, who is a nationally-acclaimed expert on air pollution regulation recalled:

\begin{abstract}
"During the days before the G20 Summit, we [the group of scientists] noted that the PM2.5 concentration in Hangzhou was still a bit too high. On the basis of our air quality modelling, we understood that this was mainly due to particles transported in by winds from the northern direction, which, according to the forecast, were to continue. The largest sources there were Jiangsu province and Shanghai city. Therefore, in order to reduce the pollution transported in, we had to call upon Jiangsu province to further accelerate measures of air pollution mitigation. Jiangsu province and Shanghai city were then instructed by the Cooperation Group for Air Pollution Protection in the Yangtze Delta Area to take urgent control measures in order to reduce the emissions of VOCs." 12
\end{abstract}

\title{
3.4 Integration of External Scientific Expertise for the Evaluation of Air Quality Control
}

The previously-mentioned team of scientific experts from Tsinghua University won the bid put out by Zhejiang Province's Environmental Protection Bureaus to design and oversee measures for smog and air quality control during the G20 summit. They were then invited by the EPB to conduct a "pre-evaluation" of the air quality in Hangzhou before 24 August 2016, a "dynamic evaluation" between 24 August and 6 September, and a "post evaluation" after 6 September 2016. This advisory team was led by senior experts from Tsinghua University and the Chinese Academy of Engineering. In addition to designing the air quality guarantee program in the run-up to the Hangzhou G20 summit, the team of scientists was resident in Hangzhou during the event, as an on-site task force, to assist Zhejiang province's EPB with its air pollution reduction efforts.

During the G20 Blue phase in Hangzhou, between 24 August and 6 September, the core expert team worked in three day cycles: on the first day, the team collected data from the meteorological forecasts and data related to real-time emissions, and ran an air quality model at approximately 8 p.m.. At 9 am the following morning, they held a consultation with Zhejiang provincial leaders, as well as MEP and EPB leaders, after which local leaders, taking into account the experts' advice, made a decision about air quality control measures at 2 p.m.. The control measures would be implemented on the third day, and usually yielded results one or two days later. It was at this point, as a further member of the team, another professor from

\footnotetext{
12 Interview on 26 June 2017.
} 
Tsinghua University, confirmed, that the government's control measures were not completely predefined and fixed, but relatively adaptable and could be changed in line with the real-time air quality data coming in: if the air quality deteriorated, more factories had to halt production and traffic had to be more strictly controlled in all the designated areas. ${ }^{13}$

\subsection{Scientifically-Grounded Mobilization of the Public for G20 Blue}

In China's environmental governance, interfaces and interaction between the Government and the public usually oscillate between conflict and cooperation (Shen \& Steuer, 2017). Consequently, in a rather proactive tactical move, Zhejiang's provincial government issued an invitation to policy experts to design specific plans to mobilize public support and legitimize all the restrictions that would be in effect during the G20 Blue enforcement campaign, by scientific and strategic means. This led, first of all, to a rather aggressive propaganda initiative. Slogans, such as "A good host, a better G20" and "Hangzhou G20 presents the world with unique splendidness” (杭州 G20 给世界一场别样的精彩) were ubiquitous at public bus stations, Hangzhou airport, and the highway gates leading to Hangzhou city. Concurrently with the appearance of these slogans, local newspapers and television programs constantly called upon the residents of Hangzhou to voluntarily sacrifice their own freedoms and happily endure the many inconveniences brought about by the governments' enforcement measures, primarily traffic controls, halts in production and forced holidays.

In the neighborhoods of Hangzhou City, all members of the community, especially the retired elderly residents, were encouraged to participate in the G20 Blue campaign. They patrolled within and around their own communities in order to detect (even small-scale) industrial air pollution or the extensive discharge of cooking oil fumes. If they noticed any infraction, they had to report this directly, so that the local EPB could take immediate action. Furthermore, all citizens in Hangzhou were urged to use public transport instead of private cars in order to reduce traffic-related air pollution during the G20 summit. ${ }^{14}$

The most extraordinary measure aimed at regulating any individual human impact on air pollution, was that residents were actively encouraged to leave the Hangzhou area for a weeklong holiday. The government shut down the city's famous West Lake sightseeing area and instead offered free travel vouchers, worth up to CNY 10 billion (\$ 1.5 billion) in total, in an

\footnotetext{
${ }^{13}$ Interview on 29 November 2016.

${ }^{14}$ According to our interviews and online BBS forum analyses, there were two main and quite contradictory reactions to public mobilization during the G20 Summit. Most commentators complained about the inconvenience that the G20 preparations entailed, while others voiced their support. The latter thought that the temporary regulations could potentially bring about some improvements in city life in the future.
} 
effort to persuade people to visit attractions outside Hangzhou. Many tourist sites across China offered discounted tickets (up to $50 \%$ reductions on the normal price) for visitors with a Hangzhou resident ID. The goal was to persuade a total of two million, out of the officially nine million, citizens of Hangzhou to leave the city during the G20 summit. And although we have not yet been able to obtain very reliable figures related to the actual mobility of residents during the G20 period, international media reported that Hangzhou had turned into a ghost town by the time the G20 leaders arrived (Campbell, 2016). ${ }^{15}$

\subsection{Documented Results of the G20 Blue Campaign}

During the 2016 G20 Hangzhou Summit, the sky above he city was indeed visibly blue and reportedly clean. The obvious success of this campaign-style smog and air quality control was celebrated in the Chinese media and - according to our own observations - by those who had been responsible for implementing the plan. Air quality in the city reached the Grade II National Ambient Air Quality Standards and PM2.5 concentration was reported to have fallen under $35 \mu \mathrm{g} / \mathrm{m}^{3}$ at times, on 3 September, for example. According to the evaluation report by the Tsinghua University advisory team, the G20 Blue control measures resulted in an overall reduction of PM 2.5 concentrations ranging down from $81 \%$ to $57 \%$ during the summit (Xu et al., 2017) (see Table 2).

Table 2: The pollutants targeted by the Hangzhou G20 Blue control measures, 2016

\begin{tabular}{|c|c|c|c|}
\hline \multirow{2}{*}{ Pollutant } & 2016 & \multicolumn{2}{|c|}{ Compared to 2015 } \\
\cline { 2 - 4 } & Conc. & Conc. & Reduction \\
\hline $\mathrm{PM}_{2.5}$ & 31 & 57 & $47 \%$ \\
\hline $\mathrm{SO}_{2}$ & 9 & 14 & $31 \%$ \\
\hline $\mathrm{NO}_{2}$ & 16 & 41 & $60 \%$ \\
\hline
\end{tabular}

Source: Data obtained from the G20 ‘task force’ team of scientists from Tsinghua University

\section{Policy Implications and Conclusions}

To achieve blue skies during the 2016 G20 summit in China, the host city of Hangzhou and

\footnotetext{
${ }^{15}$ In fact, the enforced entry and exit controls and the sheer reduction in the number of people around the G20 site was very well aligned with the government's other G20 related policies, including security measures and anti-terror defense.
} 
the surrounding regional governments built on scientifically-steered campaign-style air quality control. This paper has analyzed the ways in which the marriage of policy and science contributed to ad hoc smog clearance measures for a mega-event and the ways in which science was included and adopted by the Chinese government to ensure the efficiency and legitimacy of temporary and harsh air quality control measures.

However, many observers consider temporary high-urgency pollution regulation such as the G20 Blue to be a governmental "face-saving" strategy and quite rightfully entertain suspicions regarding the long-term effects of such projects. More pertinently, it all seems to amount to a total waste of resources. Firstly, a huge amount of public finance was invested in the campaign for a temporary blue sky over Hangzhou. Although there is no official data available with regard to the total costs of the regulation campaign, we can assume that an incredible sum of money was spent on all the various measures involved. Secondly, citizens living in Hangzhou City and the surrounding areas faced the huge inconvenience of having their mobility (especially in terms of car transportation) restricted, and their daily lives essentially came to a standstill during the G20 summit. Thirdly, factories that were forced to halt or reduce production during the G20 summit period later had to make up their economic losses. This meant that the same amount of industrial air pollution that was reduced or avoided for the G20 Blue was expected to be discharged after the G20, and maybe even at higher levels. The campaign-style pollution control created a flashy G20, staged against bright blue skies, but all of this was considered completely unsustainable. ${ }^{16}$ After the G20 summit, it was expected that all the restrictions that had been in effect during the event would be lifted and everything would go back to normal again, including the grey skies .

Nevertheless, we would like to add another perspective, and argue that - notwithstanding all the waste - scientifically-based campaign-style air pollution control can actually yield a considerable amount of positive and sustainable policy effects. Firstly, it helps to improve and strengthen the capacity to regulate polluting industries. The information about industrial pollution sources collected by the groups of scientists during the preparations for the G20 Blue is still helping the EPB in Zhejiang Province to track industrial air pollution, and it also facilitates the continuous monitoring of compliance with regulations. In addition, although this was not necessarily an intended outcome, some of the most heavily polluting industrial

\footnotetext{
16 See media reports, such as "Blue skies over Hangzhou: clearing the way for a climate-focused summit?" Global Policy Journal 3 September 2016, available at https://www.globalpolicyjournal.com/blog/03/09/2016/blue-skies-over-hangzhou-clearing-way-climate-focusedsummit (access on 14 October 2018); "Ghost town: how China emptied Hangzhou to guarantee 'perfect' G20," The Guardian 2 September 2016, available at https:/www.theguardian.com/world/2016/sep/05/ghost-town-howchina-emptied-hangzhou-to-guarantee-perfect-g20 (access on 14 October 2018).
} 
facilities were eventually shut down completely, while others were assisted with, or forced into, technological upgrading in the form of filters or improvements in the process flow of industrial air pollution reduction.

Secondly, the ability of local EPBs to implement air pollution regulations improved and new scientific knowledge was obtained that had to be understood by the staff of the local EPBs. A great deal of technical equipment and many new tools for air monitoring and analysis were purchased and brought into use as a result of the G20 summit funding, which would not have been possible through regular government procurement. The local EPB staff were pushed to learn and master new or extended technical skills and scientific methods in order to process and analyze the data obtained via the new monitoring equipment. For example, the environmental emergency capacity of local EPBs, including prophylactic and contingency planning, analysis of the emergency monitoring data, and issuing emergency information to the public, were among the aspects included in simulation training before and during the G20 summit.

Thirdly, although to a lesser degree, campaign-style smog control for the G20 summit enhanced regional coordination capacities in the Yangtze River Delta area. "Before the G20 summit, regional coordination was only a slogan, but it was put into practice and would operate sustainably, during the G20 summit and after," 17 an official from Zhejiang Province's EPB claimed. Official data obtained from the Hangzhou EPB shows that air quality measurements in the city area (i.e. the number of at least "good" AQI days/year) generally improved at a rate of $3.1 \%$ in the first half of 2017, compared with the same period in 2016, while the concentration of PM2.5 decreased by $12.3 \%$. Further research is required to establish how much of this was the legacy of G20 Blue.

Last, but certainly not least, one should not neglect the effect this quasi-experiment may have had on the general populace. Although we lack reliable survey data, it can be expected that public awareness and demands for cleaner air have increased since the experience of days of living with clean air and realizing that fabricating blue skies is politically and technically possible.

However, while we claim that our case study is representative of an increase of science-based environmental governance in China, we do not claim that science-policy integration works perfectly well in campaign-style pollution control. The fact that "blue sky fabrication" posits political interventions against natural phenomena makes planned measures, no matter how

\footnotetext{
${ }^{17}$ Interview on 31 March 2017.
} 
scientific they may be, very vulnerable to almost incalculable influences and changes (Gao et al. 2017; Liu et al. 2017). And this, for the time being, seems to lead the authorities in charge towards opting for harsher measures than potentially necessary, in order to control any risk to "blue skies" during mega events, which is still considered an image-building project, - all at enourmous public cost. Beyond that, in the course of campaign-style air quality control, political authorities so far concentrate only on those scientific inputs that are required and useful in order to reach the once defined goal, while ignoring advice that could potentially lead to improvements somewhere else. As one of the scientists involved in the G20 Blue recounted:

"we once suggested to the Zhejiang Provincial government to take further actions for controlling ozone together with PM2.5, in order to improve the air quality in general, rather than simply making the sky blue, but the Zhejiang provincial government did not react to this advice at that time. It would have taken more efforts to improve the ozone situation as well." 18

Under current political circumstances in China, this kind of tunnel vision among (local) officials seems hardly avoidable, but it is definitively a hindrance to comprehensive sciencebased environmental policy making.

Altogether, for the time being, campaign-style pollution regulation at the interfaces of policy and science seems to fit quite well with the general tendency of modern authoritarian regimes to increasingly adopt scientific knowledge and advanced technology in order to tackle pressing problems, and it appears to be a particular trait of contemporary environmental governance in China (Ahlers \& Shen, 2017). Whether it will soon be applied to other policy fields as well remains to be seen.

\footnotetext{
${ }^{18}$ Interview on 29 November 2016.
} 


\section{References}

Ahlers, A. L., Hansen, M. H., 2017. Air pollution: How will China win its self-declared war against it? In: Sternfeld, E. (ed.), Routledge Handbook of Environmental Policy in China, Routledge, London, 83-96.

Ahlers, A.L., Shen, Y., 2017. Breathe easy? Local nuances of Authoritarian Environmentalism in China's battle against air pollution. The China Quarterly, online first (https://doi.org/10.1017/S0305741017001370).

Aunan, K., Hansen, M. H., Wang S., 2017. Introduction: Air pollution in China. The China Quarterly, online first (https://doi 10.1017/S0305741017001369).

Biddulph, S., Cooney, S., Zhu, Y., 2012. Rule of law with Chinese characteristics: The role of campaigns in lawmaking. Law and Policy, 34(4), 373-401.

Caratti, P., Ferraguto, L., 2012. The role of environmental issues in mega-events planning and management processes: Which factors count? In: Hayes, G., Karamichas, J. (ed.), Olympic Games, Mega-events and Civil Societies: Globalization, Environment, Resistance, Palgrave Macmillan, London, pp. 109-125.

Campbell, J., 2016. China's Hangzhou turns ghost town as G20 leaders arrive. Reuters, 3 September. http://www.reuters.com/article/us-g20-china-hangzhou-idUSKCN11906S (accessed 15 June 2017)

Farish, M. 2013. Creating cold war climates. The laboratories of American globalism. In: McNeill, J. R., Unger, C. R. (eds.), Environmental Histories of the Cold War, Cambridge: Cambridge University Press, 51-83.

Gao M. et al. 2017. Distinguishing the roles of meteorology, emission control measures, regional transport, and co-benefits of reduced aerosol feedbacks in 'APEC Blue.' Atmospheric Environment, 167 , 476-486.

Gilley, B., 2012. Authoritarian environmentalism and China's response to climate change. Environmental Politics, 21(2), 287-307.

Guo, L., Foster, K. W., 2008. Administrative campaigns and environmental governance in contemporary China. Paper prepared for presentation at the Association for Asian Studies Annual Meeting in Atlanta, Georgia.

Hsu, A., 2014. Seeing through the smog: China's air pollution challenge for East Asia. In: Harris, P.G., Lang, G. (eds.), Routledge Handbook of Environment and Society in Asia, Routledge, London, 60-75.

Liu, H. et al. 2017. The blue skies in Beijing during APEC 2014. A quantitative assessment of emission control efficiency and meteorological influence. Atmospheric Environment, $167,235-244$. 
Liu, N. N., Lo, C. W. H., Zhan, X., Wang, W., 2015. Campaign-style enforcement and regulatory compliance. Public Administration Review, 75(1), 85-95.

Perry, E. 2011. From mass campaigns to managed campaigns: 'constructing a new socialist countryside'. In: Heilmann, S., Perry, E., (eds.), Mao's Invisible Hand. The Political Foundations of Adaptive Governance in China, Cambridge: Harvard University Press, $30-61$.

Schubert, J. 2018. Engineering the climate. Science, politics, and the historical emergence of a plan b for climate change $(1850-2015)$. Paper presented at the workshop 'The Politics of Grand Challenges', FIW - University of Bonn, 26 January.

Shen, Y., Steuer, B., 2017. Conflict or cooperation: the patterns of interaction between state and non-state actors in China's environmental governance. Journal of Chinese Governance, 2(4), 349-359.

Tanner, H. M., 1999. Strike hard! Anti-crime Campaigns and Chinese Criminal Justice, 19791985. New York: Cornell University Press.

Tanner, M. S., 2005. Campaign-style policing in China and its critics. In: Bakken, B. (ed.), Crime, Punishment, and Policing in China, MD: Rowman \& Littlefield, Lanham, 171-188.

Van Rooij, B., 2006. Implementation of Chinese environmental law: Regular enforcement and political campaigns. Development and Change, 37(1), 57-74.

Wedeman, A., 2005. Anticorruption campaigns and the intensification of corruption in China. Journal of Contemporary China, 14(42), 93-116.

Xu, S., Wang, X., and Tian, X. 2017., G20 峰会空气质量保障机制的构建 (The design of the air quality guarantee mechanism during the G20 Summit). 中国环境监测 (China environmental monitoring), 33(1), 1- 6 .

Zhu, J., Zhang, D., 2017. Weapons of the powerful: Authoritarian elite competition and politicized anticorruption in China. Comparative Political Studies, 50(9), 1186-1220. 